Article

\title{
Test-Retest Reliability of Kinematic Parameters of Timed Up and Go in People with Type 2 Diabetes
}

\author{
Francisco J. Dominguez-Muñoz ${ }^{1}$, Miguel A. Hernández-Mocholi ${ }^{1}$, Luis J. Manso ${ }^{2}{ }^{(D}$, \\ Daniel Collado-Mateo $^{3, * \mathbb{D}}$, Santos Villafaina ${ }^{1, * \mathbb{D}}$, Jose C. Adsuar ${ }^{4}\left(\mathbb{D}\right.$ and Narcis Gusi ${ }^{1,5}$ \\ 1 Physical Activity and Quality of Life Research Group (AFYCAV), Faculty of Sport Science, University of \\ Extremadura, 10003 Cáceres, Spain; fjdominguez@unex.es (F.J.D.-M.); mhmocholi@unex.es (M.A.H.-M.); \\ ngusi@unex.es (N.G.) \\ 2 School of Engineering and Applied Sciences, Aston University, Birmingham B4 7ET, UK; \\ 1.manso@aston.ac.uk \\ 3 Centre for Sport Studies, Rey Juan Carlos University, 28943 Fuenlabrada, Spain \\ 4 Health Economy Motricity and Education (HEME), Faculty of Sport Science, University of Extremadura, \\ 10003 Cáceres, Spain; jadssal@unex.es \\ 5 CIBER de Fragilidad y Envejecimiento Saludable, 28029 Madrid, Spain \\ * Correspondence: danicolladom@gmail.com (D.C.-M.); svillafaina@unex.es (S.V.); Tel.: +34-9-2725-7460
}

Received: 13 September 2019; Accepted: 1 November 2019; Published: 5 November 2019

\begin{abstract}
Diabetes mellitus is a chronic disease defined as a state of hyperglycaemia in fasting or postprandial states. Patients with type 2 diabetes mellitus (T2DM) often show reduced physical function, including low levels of strength, balance or mobility. In this regard, the timed up and go (TUG) is a widely used physical fitness test in people with T2DM. However, there is a lack of studies evaluating the properties TUG in this population. The present study aimed to evaluate the test-retest reliability of kinetic and kinematic parameters obtained from TUG in the diabetic population with different levels of diabetic neuropathy. A total of 56 patients with T2DM participated in the study. They were divided into three groups according to the vibration threshold: (a) severe neuropathy, (b) moderate neuropathy and (c) normal perception. The TUG was performed using two force platforms to assess kinematic measurements. The results show that both kinetic and kinematic variables had good to excellent reliability. The reliability of TUG was excellent for the whole sample and the groups with non-severe neuropathy. However, it was just good for the group with severe neuropathy.
\end{abstract}

Keywords: forefoot; Gait; Heel; TUG; Type 2 diabetes mellitus

\section{Introduction}

Diabetes mellitus (DM) is a chronic disease defined as a state of hyperglycaemia in fasting or postprandial states [1]. DM is one of the largest global public health problems and affects approximately 415 million people in the world among adults aged 20-79 years-old. It is estimated that, in the year 2040, there will be 642 million persons (confidence interval 521-829 million) with DM in the world [2]. The International Diabetes Federation also estimates that, globally, $46.5 \%$ of people suffering from diabetes were still undiagnosed in 2015, which may markedly increase the reported prevalence. According with the American Diabetes Association (ADA), the total costs for diabetes care in the United States were approximately 245 billion dollars due to medical costs, lost productivity and disability [3]. Much of the burden of this disease comes from vascular complications, which include cardiovascular disease, retinopathy and nephropathy. Another complication is diabetic peripheral neuropathy, affecting more than 50\% of long-term diabetic cases [4]. 
Diabetic neuropathy is characterised by progressive degeneration that primarily affects small-diameter cutaneous nociceptive fibres [5]. It may also affect motor fibres, which can cause muscular weakness. In this regard, persons with DM have a reduction of $17 \%$ and $14 \%$ in the strength of the flexor and extensor muscles of the knee, respectively [6]. Somatosensory feedback is a relevant factor to maintain balance and there is strong evidence showing that diabetic neuropathy affects this source of information, leading to alterations in postural and gait performance [7]. In this regard, previous studies have demonstrated that the main sources of deterioration in the balance in persons with type $2 \mathrm{DM}$ (T2DM) are deficits in the proprioception of the foot and the ankle [8], or a loss of sensitivity in the feet [9].

The neurologic exam of the lower limb is the most important aspect in the clinical diagnosis of diabetic neuropathy [10]. The loss of foot vibration perception is associated with an increased risk of foot ulceration in people with diabetes [11]. In this regard, Abbott et al. [12] showed that each one-unit increment in the foot vibration threshold increases the risk of foot ulceration by more than $5 \%$ in a single year period. Therefore, the foot vibration threshold is a very relevant variable in the diabetic population.

Previous studies have demonstrated a relationship between the foot vibration threshold and the risk of falling [13], gait speed [14] and mobility disability [15]. Although balance and mobility tests are of great interest in DM studies due to the association with the risk of falling and the ability to perform activities of daily living, a recent systematic review showed that there is a lack of studies evaluating the properties of these tests when they are conducted in the diabetic population [16].

Therefore, the main objective of this study was to evaluate the test-retest reliability of the kinetic and kinematic parameters obtained from one of the most widely used tests for assessing balance and mobility, the timed up and go (TUG), in people suffering from T2DM. The second objective was to calculate the reliability of TUG according to the severity of peripheral neuropathy (assessed through an evaluation of the foot vibration threshold).

\section{Materials and Methods}

\subsection{Participants}

A total of 56 patients with DM participated in the study. Of these, 40 were men and 16 were women. The following inclusion criteria were: (a) diagnosed with T2DM, (b) affected by at least one risk factor of diabetic neuropathy: (1) being overweight, (2) a former smoker, (3) diagnosed with diabetic nephropathy and (4) diagnosed with diabetic retinopathy, (c) levels of glycated haemoglobin higher than 5.7\%, and (d) have read and signed the written informed consent. In addition to these inclusion criteria, some exclusion criteria were defined: (a) pregnancy, (b) the use of psychotropic or chemotherapeutic medications, (c) affected by other diseases that may influence balance and gait, such as Parkinson's disease, and (d) patients with a high risk of non-diabetic neuropathy (HIV or uraemia). The protocol of the present study was approved by the Committee of Bioethics of the University and was developed in accordance with the updated Helsinki Declaration and the national legislation on bioethics, biomedical research and personal data confidentiality.

\subsection{Procedure}

After reading and signing the written informed consent, participants were measured and weighed. They were also asked about their age and years since diagnosis. Then, the vibration threshold was evaluated and, finally, the TUG was conducted after a light warm-up.

The foot vibration threshold was assessed using a Biothensiometer Vibratron II (Physitemp Instruments, Inc. Clifton; New Jersey; USA). This device drives vibration to modules A and B placed under the feet of the participant. Each module has a vibrating pole on the top, which vibrates at a frequency of $120 \mathrm{~Hz}$. Therefore, the vibration threshold is determined by modifying the amplitude. These vibration units are related to the amplitude of the movement in microns according to the formula: 
$A=x^{2} / 2$ (where $\mathrm{x}$ is the vibration units (vu) and $\mathrm{A}$ is the amplitude in microns $(\mu \mathrm{m})$ ). The present study used the protocol the 'force two alternative choices procedure', which is one of the two methods suggested by the manufacturer. Participants were asked to place their first toe on the vibrating pole. The procedure started when the participant felt the vibration in the left or right toe. After that, the amplitude was reduced progressively until the participant was not able to tell which pole was vibrating. When the participant failed to detect vibration, the amplitude of the vibration was increased. The vibration threshold was then calculated using the last five rights and wrongs, but omitting the extreme low and high values. The average of the remaining eight values was then computed to calculate the vibration threshold [17].

TUG was performed three times, with a 5-min rest in between. The first repetition was for familiarisation, the second was the test measure and the third was the retest measure. All participants performed a light warm-up which included walking and joint mobility for $5 \mathrm{~min}$. In the TUG, two force platforms (Kistler, NY, USA) were placed between the chair and the mark where participants had to turn around. Therefore, participants stepped on the platforms before and after reaching the mark placed at $3 \mathrm{~m}$. The time required to complete the full test was assessed manually with a stopwatch by an expert rater.

Variables obtained from the force platforms included the duration of (a) the double support phase (both feet on the platforms), (b) left support (only the left foot on the platforms) and (c) right support (only the right foot on the platforms), as well as the left and right peak forces from the forefoot and the heel.

The results are presented for the whole sample $(n=56)$, and also according to the degree of neuropathy based on vibration perception, i.e., severe neuropathy $(n=22)$, moderate neuropathy $(n=22)$ and normal perception $(n=12)$. To classify patients into one of the three groups, the cut-off points suggested by normative values of the manual of the measuring device were considered.

\subsection{Statistical Analysis}

Descriptive statistics included mean and standard deviation (SD) of age, weight, glycated haemoglobin, years since T2DM diagnosis, body mass index and vibration threshold were calculated for the whole sample and divided into women or men. Parametric and non-parametric tests were conducted based on the results of Shapiro-Wilk and Kolmogorov-Smirnov tests.

Differences between test and retest were evaluated using the paired samples t-test or Wilcoxon signed rank test when appropriate. The time spent to complete the TUG, the duration of phases and the forces registered by the force platforms were included in those analyses to compare the test and retest results.

Reliability analyses were conducted in accordance with the recommendations of Weir [18]. An intraclass correlation coefficient (ICC) of 3.1 (two-way mixed, single measures) with a 95\% CI for test and retest [19] was selected. Both absolute and relative reliability were computed. The standard error of measurement (SEM) was calculated as $S E M=S D \sqrt{1-I C C}$ where SD is the mean SD of the three repetitions, while the smallest real difference (SRD) was $S R D=1.96 \times S E M \times \sqrt{2}$. These measures were converted into percentages (\%SEM and \%SRD, respectively) to enable comparisons with other investigations.

\section{Results}

\subsection{Participant Characteristics}

Table 1 summarises the participant characteristics. A total of 40 men and 16 women aged 64.52 (8.41) and 67.43 (8.86), respectively, participated in the present study. The mean weight of the whole sample was $80.08(17.59) \mathrm{kg}$ and the body mass index (BMI) was $28.81(4.40) \mathrm{kg} / \mathrm{m}^{2}$. The mean vibration threshold was 4.27 (1.90) for women and 5.75 (2.50) for men. 
Table 1. Participant characteristics.

\begin{tabular}{cccc}
\hline & All Participants $(\boldsymbol{n = 5 6 )}$ & Men $(\boldsymbol{n = 4 0 )}$ & Women $(\boldsymbol{n}=\mathbf{1 6})$ \\
\hline Age (years) & $65.35(8.56)$ & $64.52(8.41)$ & $67.43(8.86)$ \\
Weight $(\mathrm{kg})$ & $80.08(17.59)$ & $85.26(18.03)$ & $67.11(6.14)$ \\
Glycated haemoglobin $(\%)$ & $6.66(0.91)$ & $6.67(0.90)$ & $6.63(0.94)$ \\
Years since diagnosis & $9.10(7.43)$ & $9.07(6.52)$ & $9.18(9.59)$ \\
BMI $\left(\mathrm{kg} / \mathrm{m}^{2}\right)$ & $28.81(4.40)$ & $29.24(4.84)$ & $27.73(2.85$ \\
Vibration threshold $(\mathrm{vu})$ & $5.33(2.42)$ & $5.75(2.50)$ & $4.27(1.90)$ \\
\hline
\end{tabular}

BMI: body mass index; vu: vibration units.

\subsection{Kinematic Variables of the Timed Up and Go}

Table 2 summarises the mean duration of the walking phases in the TUG. The results from the paired samples $t$-test or Wilcoxon signed rank test showed that there were significant differences between the test and retest values in some of the variables, including the time required to complete the TUG and the duration of the left support before reaching the mark for the whole sample. These differences were also observed in the group with severe neuropathy.

Table 2. Differences between test and retest on the duration of the walking phases in the entire sample and in participants with (a) severe neuropathy, (b) moderate neuropathy and (c) normal perception.

\begin{tabular}{|c|c|c|c|c|}
\hline & Test Measurement & Test & Retest & $p$-Value ${ }^{\text {a }}$ \\
\hline \multirow{7}{*}{ GENERAL $(n=56)$} & TUG (S) & $8.10(1.37)$ & $7.80(1.28)$ & $<0.001$ \\
\hline & Double support phase duration (before reaching the mark) & $0.09(0.02)$ & $0.09(0.02)$ & $0.341^{\mathrm{a}}$ \\
\hline & Double support phase duration (after reaching the mark) & $0.10(0.02)$ & $0.10(0.02)$ & $0.483^{\mathrm{a}}$ \\
\hline & Right support duration (before reaching the mark) & $0.62(0.09)$ & $0.60(0.09)$ & $0.047^{\mathrm{a}}$ \\
\hline & Left support duration (before reaching the mark) & $0.62(0.09)$ & $0.60(0.08)$ & $0.005^{\mathrm{a}}$ \\
\hline & Right support duration (after reaching the mark) & $0.62(0.08)$ & $0.61(0.08)$ & 0.261 \\
\hline & Left support duration (after reaching the mark) & $0.63(0.09)$ & $0.63(0.10)$ & $0.399^{\mathrm{a}}$ \\
\hline \multirow{7}{*}{ SEVERE $(n=22)$} & TUG (S) & $8.36(1.40)$ & $7.94(1.10)$ & 0.007 \\
\hline & Double support phase duration (before reaching the mark) & $0.09(0.02)$ & $0.09(0.02)$ & $0.463^{\mathrm{a}}$ \\
\hline & Double support phase duration (after reaching the mark) & $0.10(0.02)$ & $0.10(0.02)$ & $0.637^{\mathrm{a}}$ \\
\hline & Right support duration (before reaching the mark) & $0.62(0.09)$ & $0.60(0.08)$ & $0.117^{\mathrm{a}}$ \\
\hline & Left support duration (before reaching the mark) & $0.63(0.08)$ & $0.60(0.06)$ & $0.020^{\mathrm{a}}$ \\
\hline & Right support duration (after reaching the mark) & $0.62(0.06)$ & $0.62(0.06)$ & 0.610 \\
\hline & Left support duration (after reaching the mark) & $0.62(0.06)$ & $0.63(0.08)$ & $0.986^{\mathrm{a}}$ \\
\hline \multirow{7}{*}{$\begin{array}{l}\text { MODERATE } \\
\quad(n=22)\end{array}$} & TUG (S) & $7.92(1.47)$ & $7.69(1.54)$ & 0.016 \\
\hline & Double support phase duration (before reaching the mark) & $0.09(0.03)$ & $0.09(0.02)$ & $0.930^{\mathrm{a}}$ \\
\hline & Double support phase duration (after reaching the mark) & $0.10(0.02)$ & $0.10(0.03)$ & $0.974^{\mathrm{a}}$ \\
\hline & Right support duration (before reaching the mark) & $0.61(0.10)$ & $0.60(0.11)$ & $0.443^{\mathrm{a}}$ \\
\hline & Left support duration (before reaching the mark) & $0.60(0.11)$ & $0.60(0.11)$ & $0.750^{\mathrm{a}}$ \\
\hline & Right support duration (after reaching the mark) & $0.61(0.10)$ & $0.61(0.10)$ & 0.697 \\
\hline & Left support duration (after reaching the mark) & $0.64(0.12)$ & $0.64(0.12)$ & $0.650^{\mathrm{a}}$ \\
\hline \multirow{7}{*}{ NORMAL $(n=12)$} & TUG (S) & $7.94(1.16)$ & $7.74(1.15)$ & 0.095 \\
\hline & Double support phase duration (before reaching the mark) & $0.09(0.01)$ & $0.08(0.01)$ & $0.260^{\mathrm{a}}$ \\
\hline & Double support phase duration (after reaching the mark) & $0.10(0.01)$ & $0.09(0.02)$ & $0.164^{\mathrm{a}}$ \\
\hline & Right support duration (before reaching the mark) & $0.63(0.09)$ & $0.61(0.07)$ & $0.153^{\mathrm{a}}$ \\
\hline & Left support duration (before reaching the mark) & $0.62(0.06)$ & $0.59(0.06)$ & $0.025^{a}$ \\
\hline & Right support duration (after reaching the mark) & $0.61(0.05)$ & $0.60(0.06)$ & 0.235 \\
\hline & Left support duration (after reaching the mark) & $0.63(0.08)$ & $0.62(0.09)$ & $0.312^{\mathrm{a}}$ \\
\hline
\end{tabular}

a $p$-values obtained from the Wilcoxon signed rank test.

Reliability parameters for the total time required to complete the TUG and duration of phases can be observed in Table 3. The ICC was good (0.70 to 0.90$)$ or excellent $(>0.90)$ for almost every variable and group. The best reliability was obtained for the time required to complete the TUG, which was excellent in the two groups with non-severe neuropathy, while it was just good in the group with severe neuropathy. 
Table 3. Test-retest analyses of the duration of the walking phases in the entire sample and in participants with (a) severe neuropathy, (b) moderate neuropathy and (c) normal perception.

\begin{tabular}{|c|c|c|c|c|c|c|}
\hline & Test Measurement & $\operatorname{ICC}(95 \% \mathrm{CI})$ & SEM (s) & SEM (\%) & SRD (s) & SRD $(\%)$ \\
\hline \multirow{6}{*}{ GENERAL $(n=56)$} & TUG (S) & $0.927(0.878-0.956)$ & 0.36 & 4.52 & 0.99 & 12.55 \\
\hline & Double support phase duration (going) & $0.760(0.623-0.852)$ & 0.01 & 14.07 & 0.03 & 39.02 \\
\hline & Double support phase duration (return) & $0.801(0.683-0.878)$ & 0.01 & 10.73 & 0.03 & 29.74 \\
\hline & Left support duration (before reaching the mark) & $0.845(0.749-0.906)$ & 0.03 & 5.80 & 0.09 & 16.08 \\
\hline & Right support duration (after reaching the mark) & $0.876(0.798-0.925)$ & 0.02 & 4.71 & 0.08 & 13.05 \\
\hline & Left support duration (after reaching the mark) & $0.860(0.772-0.915)$ & 0.03 & 5.77 & 0.10 & 16.01 \\
\hline \multirow{5}{*}{ SEVERE $(n=22)$} & Double support phase duration (return) & $0.853(0.678-0.936)$ & 0.01 & 7.60 & 0.02 & 21.07 \\
\hline & Right support duration (before reaching the mark) & $0.782(0.544-0.903)$ & 0.04 & 6.58 & 0.11 & 18.25 \\
\hline & Left support duration (before reaching the mark) & $0.730(0.454-0.879)$ & 0.04 & 6.63 & 0.11 & 18.38 \\
\hline & Right support duration (after reaching the mark) & $0.853(0.678-0.936)$ & 0.02 & 4.07 & 0.07 & 11.30 \\
\hline & Left support duration (after reaching the mark) & $0.727(0.448-0.877)$ & 0.03 & 6.01 & 0.10 & 16.66 \\
\hline \multirow{2}{*}{$\begin{array}{l}\text { MODERATE } \\
\quad(n=22)\end{array}$} & Right support duration (after reaching the mark) & $0.903(0.781-0.959)$ & 0.03 & 5.43 & 0.09 & 15.06 \\
\hline & Left support duration (after reaching the mark) & $0.912(0.800-0.962)$ & 0.03 & 5.71 & 0.10 & 15.83 \\
\hline \multirow{7}{*}{ NORMAL $(n=12)$} & TUG (S) & $0.938(0.800-0.982)$ & 0.28 & 3.67 & 0.79 & 10.17 \\
\hline & Double support phase duration (going) & $0.565(0.018-0.852)$ & 0.01 & 11.93 & 0.02 & 33.08 \\
\hline & Double support phase duration (return) & $0.511(0.059-0.829)$ & 0.01 & 15.04 & 0.04 & 41.69 \\
\hline & Right support duration (before reaching the mark) & $0.880(0.636-0.964)$ & 0.03 & 4.82 & 0.08 & 13.38 \\
\hline & Left support duration (before reaching the mark) & $0.881(0.639-0.964)$ & 0.02 & 3.70 & 0.06 & 10.25 \\
\hline & Right support duration (after reaching the mark) & $0.774(0.387-0.929)$ & 0.02 & 4.64 & 0.07 & 12.88 \\
\hline & Left support duration (after reaching the mark) & $0.843(0.543-0.952)$ & 0.03 & 5.68 & 0.09 & 15.76 \\
\hline
\end{tabular}

\subsection{Peak Forces from the Heel and the Forefoot in the Timed Up and Go}

Regarding the peak forces from the heel and the forefoot, differences between test and retest were only observed for the right heel and left forefoot forces in the group without neuropathy. For the rest of the variables, the retest was not significantly different than the test (see Table 4).

Table 4. Differences between the test and retest on the peak forces from the heel and the forefoot forces in the entire sample and in participants with (a) severe neuropathy, (b) moderate neuropathy and (c) normal perception.

\begin{tabular}{lcccc}
\hline & Test Measurement in Newtons & Test & Retest & $p$-Value \\
\hline & Right forefoot forces (before reaching the mark) & $846.91(185.68)$ & $841.62(192.78)$ & $0.525^{\mathrm{a}}$ \\
& Left forefoot forces (before reaching the mark) & $827.33(195.94)$ & $828.06(187.55)$ & $0.562^{\mathrm{a}}$ \\
& Right forefoot forces (after reaching the mark) & $823.69(181.65)$ & $819.28(174.34)$ & $0.707^{\mathrm{a}}$ \\
GENERAL $(n=56)$ & Left forefoot forces (after reaching the mark) & $773.50(179.97)$ & $767.44(179.11)$ & $0.458^{\mathrm{a}}$ \\
& Right heel forces (before reaching the mark) & $881.64(201.23)$ & $902.94(209.41)$ & $0.058^{\mathrm{a}}$ \\
& Left heel forces (before reaching the mark) & $934.64(217.76)$ & $944.97(217.63)$ & $0.098^{\mathrm{a}}$ \\
& Right heel forces (after reaching the mark) & $938.52(226.32)$ & $940.87(211.95)$ & $0.579^{\mathrm{a}}$ \\
& Left heel forces (after reaching the mark) & $937.35(210.51)$ & $943.70(214.06)$ & $0.458^{\mathrm{a}}$ \\
\hline \multirow{5}{*}{ SEVERE $(n=22)$} & Right forefoot forces (before reaching the mark) & $868.77(198.23)$ & $867.59(215.78)$ & $0.833^{\mathrm{a}}$ \\
& Left forefoot forces (before reaching the mark) & $879.37(208.31)$ & $857.73(204.77)$ & $0.291^{\mathrm{a}}$ \\
& Right forefoot forces (after reaching the mark) & $855.99(204.95)$ & $849.56(204.22)$ & $0.615^{\mathrm{a}}$ \\
& Left forefoot forces (after reaching the mark) & $821.39(199.56)$ & $820.55(194.15)$ & $0.783^{\mathrm{a}}$ \\
& Right heel forces (before reaching the mark) & $937.91(209.96)$ & $958.33(237.64)$ & $0.485^{\mathrm{a}}$ \\
& Left heel forces (before reaching the mark) & $994.51(229.16)$ & $1004.19(232.83)$ & $0.338^{\mathrm{a}}$ \\
& Right heel forces (after reaching the mark) & $991.13(263.60)$ & $973.35(237.58)$ & $0.548^{\mathrm{a}}$ \\
& Left heel forces (after reaching the mark) & $983.31(226.01)$ & $979.73(219.78)$ & $0.783^{\mathrm{a}}$ \\
\hline
\end{tabular}


Table 4. Cont.

\begin{tabular}{|c|c|c|c|c|}
\hline & Test Measurement in Newtons & Test & Retest & $p$-Value \\
\hline \multirow{8}{*}{$\begin{array}{l}\text { MODERATE } \\
\quad(n=22)\end{array}$} & Right forefoot forces (before reaching the mark) & $846.14(212.30)$ & $827.06(207.90)$ & $0.178^{\mathrm{a}}$ \\
\hline & Left forefoot forces (before reaching the mark) & $809.70(215.55)$ & $819.77(205.52)$ & $0.638^{\mathrm{a}}$ \\
\hline & Right forefoot forces (after reaching the mark) & $820.03(187.24)$ & $809.08(174.89)$ & $0.527^{\mathrm{a}}$ \\
\hline & Left forefoot forces (after reaching the mark) & 747.40 (193.17) & $741.54(185.78)$ & $0.200^{\mathrm{a}}$ \\
\hline & Right heel forces (before reaching the mark) & $860.34(204.46)$ & $877.55(202.41)$ & $0.408^{\mathrm{a}}$ \\
\hline & Left heel forces (before reaching the mark) & $919.46(221.58)$ & $934.12(221.63)$ & $0.168^{\mathrm{a}}$ \\
\hline & Right heel forces (after reaching the mark) & $935.64(208.33)$ & $938.26(211.80)$ & $0.961^{\mathrm{a}}$ \\
\hline & Left heel forces (after reaching the mark) & $929.66(206.01)$ & $947.18(225.00)$ & $0.200^{\mathrm{a}}$ \\
\hline \multirow{8}{*}{ NORMAL $(n=12)$} & Right forefoot forces (before reaching the mark) & $808.24(93.51)$ & $820.69(110.33)$ & $0.136^{\mathrm{a}}$ \\
\hline & Left forefoot forces (before reaching the mark) & $764.25(100.23)$ & $788.90(107.78)$ & $0.006^{\mathrm{a}}$ \\
\hline & Right forefoot forces (after reaching the mark) & $771.20(112.84)$ & $782.47(102.16)$ & $0.388^{\mathrm{a}}$ \\
\hline & Left forefoot forces (after reaching the mark) & $733.56(83.56)$ & $717.58(113.36)$ & $0.754^{\mathrm{a}}$ \\
\hline & Right heel forces (before reaching the mark) & $817.53(163.63)$ & $847.94(150.04)$ & $0.099^{\text {a }}$ \\
\hline & Left heel forces (before reaching the mark) & $852.69(167.82)$ & $856.27(153.98)$ & $0.695^{\mathrm{a}}$ \\
\hline & Right heel forces (after reaching the mark) & 847.34 (161.18) & 886.09 (160.69) & $0.034^{\mathrm{a}}$ \\
\hline & Left heel forces (after reaching the mark) & $867.18(182.55)$ & $871.26(178.58)$ & $0.754^{\mathrm{a}}$ \\
\hline
\end{tabular}

a $p$-values obtained from the Wilcoxon signed rank test.

Table 5 summarises the reliability analyses of the kinetic variables for the whole sample and according to the neuropathy classification. Reliability was excellent (ICC >0.90) in almost every variable and group, except for the left forefoot forces after reaching the mark in the group with normal vibration perception.

Table 5. Test-retest analyses on the peak forces from the heel and the forefoot forces in the entire sample and in participants with (a) severe neuropathy, (b) moderate neuropathy and (c) normal perception.

\begin{tabular}{|c|c|c|c|c|c|c|}
\hline & Test Measurement in Newtons & $\operatorname{ICC}(95 \% \mathrm{CI})$ & SEM (N) & SEM (\%) & SRD (N) & SRD $(\%)$ \\
\hline \multirow{6}{*}{ GENERAL $(n=56)$} & Right forefoot forces (before reaching the mark) & $0.937(0.894-0.962)$ & 47.49 & 5.62 & 131.65 & 15.59 \\
\hline & Left forefoot forces (before reaching the mark) & $0.944(0.906-0.967)$ & 45.37 & 5.48 & 125.77 & 15.19 \\
\hline & Right forefoot forces (after reaching the mark) & $0.955(0.925-0.974)$ & 37.75 & 4.59 & 104.66 & 12.74 \\
\hline & Right heel forces (before reaching the mark) & $0.946(0.910-0.968)$ & 47.71 & 5.34 & 132.25 & 14.82 \\
\hline & Left heel forces (before reaching the mark) & $0.941(0.901-0.965)$ & 52.87 & 5.62 & 146.57 & 15.59 \\
\hline & Right heel forces (after reaching the mark) & $0.935(0.892-0.961)$ & 55.86 & 5.94 & 154.86 & 16.48 \\
\hline \multirow{6}{*}{ SEVERE $(n=22)$} & Left forefoot forces (before reaching the mark) & $0.937(0.854-0.973)$ & 51.84 & 5.96 & 143.69 & 16.54 \\
\hline & Right forefoot forces (after reaching the mark) & $0.968(0.925-0.987)$ & 36.59 & 4.29 & 101.44 & 11.89 \\
\hline & Left forefoot forces (after reaching the mark) & $0.973(0.936-0.989)$ & 32.34 & 3.94 & 89.66 & 10.92 \\
\hline & Right heel forces (before reaching the mark) & $0.947(0.878-0.978)$ & 51.52 & 5.43 & 142.81 & 15.06 \\
\hline & Left heel forces (before reaching the mark) & $0.959(0.903-0.983)$ & 46.77 & 4.68 & 129.64 & 12.97 \\
\hline & Right heel forces (after reaching the mark) & $0.933(0.846-0.972)$ & 64.86 & 6.60 & 179.79 & 18.30 \\
\hline \multirow{5}{*}{$\begin{array}{l}\text { MODERATE- } \\
\quad(n=22)\end{array}$} & Left forefoot forces (after reaching the mark) & $0.939(0.858-0.974)$ & 46.79 & 6.28 & 129.71 & 17.42 \\
\hline & Right heel forces (before reaching the mark) & $0.947(0.878-0.978)$ & 46.83 & 5.38 & 129.81 & 14.93 \\
\hline & Left heel forces (before reaching the mark) & $0.913(0.803-0.963)$ & 65.36 & 7.05 & 181.18 & 19.54 \\
\hline & Right heel forces (after reaching the mark) & $0.945(0.873-0.977)$ & 49.26 & 5.25 & 136.55 & 14.57 \\
\hline & Left heel forces (after reaching the mark) & $0.960(0.906-0.983)$ & 43.10 & 4.59 & 119.47 & 12.73 \\
\hline \multirow{7}{*}{ NORMAL $(n=12)$} & Right forefoot forces (before reaching the mark) & $0.931(0.778-0.980)$ & 26.77 & 3.28 & 74.20 & 9.11 \\
\hline & Left forefoot forces (before reaching the mark) & $0.976(0.920-0.993)$ & 16.11 & 2.07 & 44.66 & 5.75 \\
\hline & Right forefoot forces (after reaching the mark) & $0.926(0.765-0.978)$ & 29.24 & 3.76 & 81.06 & 10.43 \\
\hline & Left forefoot forces (after reaching the mark) & $0.697(0.234-0.902)$ & 54.20 & 7.47 & 150.24 & 20.70 \\
\hline & Right heel forces (before reaching the mark) & $0.915(0.732-0.975)$ & 45.72 & 5.49 & 126.74 & 15.22 \\
\hline & Left heel forces (before reaching the mark) & $0.934(0.789-0.981)$ & 41.33 & 4.83 & 114.57 & 13.40 \\
\hline & Right heel forces (after reaching the mark) & $0.931(0.778-0.980)$ & 42.27 & 4.87 & 117.17 & 13.51 \\
\hline
\end{tabular}

\section{Discussion}

The present study aimed to evaluate the test-retest reliability of kinetic and kinematic parameters obtained from TUG in the diabetic population. The results were analysed according to the severity of 
neuropathy. The main finding was that almost each variable achieved good (ICC between 0.70 and $0.90)$ or excellent $(>0.90)$ reliability considering the classification by Munro et al. [20].

The reliability of TUG seemed to be conditioned by the severity of neuropathy since the ICC was higher than 0.90 (excellent) for participants with moderate neuropathy and patients with normal foot vibration perception, but just good (0.70 to 0.90$)$ for patients with severe neuropathy. Therefore, although the TUG is reliable in T2DM patients, changes in the duration of the phases (single and double support) must be taken with caution since the \%SEM may be relatively high in some cases (over 10\%). Furthermore, we can observe how the SRD of the required time to complete the TUG was higher in patients with severe neuropathy. These results must be considered by clinicians and researchers in order to interpret their results when using TUG in the T2DM population. This is relevant since a previous study showed that patients with diabetic neuropathy have worse health-related quality of life and lower functional status than patients without diabetic neuropathy [21]. Neuropathy leads to balance impairments [22], gait and mobility alterations [23,24] and an increased risk of falls [25]. In addition, patients with T2DM seem to be more susceptible to falls and consequently to bone fractures [26-28]. Due to the relevance of diabetic neuropathy in patients with T2DM, future studies aimed at improving physical conditioning variables should consider that the smallest clinically relevant improvement may be higher in T2DM patients with this complication.

To our knowledge, this is the first study to assess the reliability of TUG according to the severity of neuropathy. Only one previous study has evaluated the reliability of TUG in the diabetic population [29]. That study was conducted on a sample of 18 older adults with T2DM, and no classification of the participants was performed. Furthermore, that study only evaluated the time needed to complete the TUG and not any other measure such as the duration of walking phases or kinetic parameters. Comparing results from the present study with those obtained by Alfonso-Rosa, Del Pozo-Cruz, Del Pozo-Cruz, Sanudo and Rogers [29], both studies report excellent reliability. However, the ICC and $\%$ SEM from that study were 0.98 and 3.5\%, respectively, whereas the present study reports an ICC of 0.927 and a \%SEM of 4.52. Therefore, the reliability is slightly lower in this study, which may be linked to the greater heterogeneity of the sample in the current study. In this regard, it must be noted that the study by Alfonso-Rosa, Del Pozo-Cruz, Del Pozo-Cruz, Sanudo and Rogers [29] was conducted on 18 older adults with T2DM, while the current one was conducted with 56 adults aged 65.35 (8.56) years.

The current study reported not only the SEM but also the SRD, which is extremely relevant for clinicians and researchers since it indicates whether the differences obtained as a consequence of an intervention program could be considered clinically important [30]. A previous study in T2DM [29] established the SRD for the TUG at 9.8\%, whereas in the present study the SRD was $12.55 \%$. This difference could be also explained by the heterogeneity of the sample in the current study. In this regard, the results from the previous study were limited to older adults. Thus, those studies conducted with samples comprised of adults (but not limited older adults) had no information about the reliability and the minimal clinically important difference to interpret their results. Therefore, the current study was needed since it is the first to provide reliability information in a sample comprised of adults (not limited to older adults).

Test-retest analyses have been also reported in kinematic parameters, taking into account the heel and the forefoot forces during the TUG. The results revealed that the reliability of the heel and forefoot forces could be considered as excellent, so future studies can confidently use this as a measurement to evaluate gait patterns in T2DM patients. People with diabetic neuropathy often have balance problems while performing common activities such as walking or ascending/descending stairs [31]. Furthermore, the postural mechanisms at the ankle joints are impaired in diabetic neuropathy patients during quiet standing [32]. Thus, postural instability and gait imbalance in diabetic neuropathy may contribute to a high risk of fall incidence, especially in the geriatric population $[7,31]$. Therefore, future studies should be focused on the implementation of interventions aimed to modify gait parameters to reduce the risk of falling in T2DM patients. The current study provides useful information in order to interpret 
changes achieved after a specific program, stating the minimal clinically relevant change for kinetic and kinematic variables.

The present study has two main limitations. First, although the sample size $(n=56)$ was sufficient to conduct this test-retest reliability analysis, the group with no alteration in the foot vibration threshold was comprised of only 12 people. The second limitation may be related to the inclusion criteria and the difficulty in determining that peripheral neuropathy is caused by diabetes. Even though the inclusion and exclusion criteria were very restrictive (excluding people with other diseases and people who were taking drugs that may potentially affect balance and gait), there could be other non-diagnosed diseases, environmental factors or healthy/unhealthy habits that may increase or reduce neuropathy. In spite of these two limitations, this study succeeded at reporting reliability parameters according to the severity of neuropathy in patients with T2DM.

\section{Conclusions}

The reliability of TUG was excellent for the whole sample and the groups with non-severe neuropathy. However, it was just good for the group with severe neuropathy. Regarding the kinetic and kinematic parameters, the reliability was good or excellent for almost every variable and group. The present study reports the minimal change that may be considered real (SRD) and the SEM, which should be considered by future studies aimed to assess the effects of interventions on different variables related to the TUG.

Author Contributions: F.J.D.-M., J.C.A., M.A.H.-M. conceived the study. F.J.D.-M., S.V. and D.C.-M. collected the data. F.J.D.-M., N.G., L.J.M., D.C.-M. analysed the data. S.V., N.G. and D.C.-M. designed the figures and tables. F.J.D.-M., J.C.A. and D.C.-M. wrote the manuscript. S.V., M.A.H.-M., L.J.M., and N.G. provided critical revisions on successive drafts. All authors approved the manuscript in its final form.

Acknowledgments: The author SV is supported by a grant from the regional Department of Economy and Infrastructure of the Government of Extremadura and European Social Fund (PD16008). We are grateful to the Primary Care Centre "Manuel Encinas" in Cáceres for helping recruit the participants for this study. The funders had no role in study design, data collection and analysis, decision to publish, or preparation of the manuscript.

Conflicts of Interest: The authors declare no competing interests.

\section{Abbreviations}

$\begin{array}{ll}\text { ADA } & \text { American Diabetes Association } \\ \text { BMI } & \text { Body mass index } \\ \text { DM } & \text { Diabetes mellitus } \\ \text { ICC } & \text { Intraclass correlation coefficient } \\ \text { T2DM } & \text { Type 2 diabetes mellitus } \\ \text { TUG } & \text { Timed up and go } \\ \text { SEM } & \text { Standard error of measurement } \\ \text { SPSS } & \text { Statistical Package for Social Sciences } \\ \text { SRD } & \text { Smallest real difference }\end{array}$

\section{References}

1. Alam, U.; Asghar, O.; Azmi, S.; Malik, R.A. General aspects of diabetes mellitus. Handb. Clin. Neurol. 2014, 126, 211-222. [CrossRef] [PubMed]

2. Ogurtsova, K.; da Rocha Fernandes, J.D.; Huang, Y.; Linnenkamp, U.; Guariguata, L.; Cho, N.H.; Cavan, D.; Shaw, J.E.; Makaroff, L.E. IDF Diabetes Atlas: Global estimates for the prevalence of diabetes for 2015 and 2040. Diabetes Res. Clin. Pract. 2017, 128, 40-50. [CrossRef] [PubMed]

3. ADA. American Diabetes Association: Economic costs of diabetes in the US in 2012. Diabetes Care 2013, 36, 1033-1046.

4. Boulton, A.J.; Malik, R.A.; Arezzo, J.C.; Sosenko, J.M. Diabetic somatic neuropathies. Diabetes Care 2004, 27, 1458-1486. [CrossRef] 
5. Thomas, P.K. Classification, differential diagnosis, and staging of diabetic peripheral neuropathy. Diabetes 1997, 46 (Suppl. 2), S54-S57. [CrossRef]

6. Andersen, H.; Nielsen, S.; Mogensen, C.E.; Jakobsen, J. Muscle strength in type 2 diabetes. Diabetes 2004, 53, 1543-1548. [CrossRef] [PubMed]

7. Mustapa, A.; Justine, M.; Mohd Mustafah, N.; Jamil, N.; Manaf, H. Postural control and gait performance in the diabetic peripheral neuropathy: A systematic review. BioMed Res. Int. 2016, 2016, 9305025. [CrossRef] [PubMed]

8. Van Deursen, R.; Simoneau, G.G. Foot and ankle sensory neuropathy, proprioception, and postural stability. J. Orthop. Sports Phys. Ther. 1999, 29, 718-726. [CrossRef]

9. Ducic, I.; Short, K.W.; Dellon, A.L. Relationship between loss of pedal sensibility, balance, and falls in patients with peripheral neuropathy. Ann. Plast. Surg. 2004, 52, 535-540. [CrossRef]

10. Boulton, A.J.M. Chapter 8-Diabetic neuropathy and foot complications. In Handbook of Clinical Neurology; Zochodne, D.W., Malik, R.A., Eds.; Elsevier: Amsterdam, The Netherlands, 2014; Volume 126, pp. 97-107.

11. Young, M.J.; Breddy, J.L.; Veves, A.; Boulton, A.J. The prediction of diabetic neuropathic foot ulceration using vibration perception thresholds. A prospective study. Diabetes Care 1994, 17, 557-560. [CrossRef]

12. Abbott, C.A.; Vileikyte, L.; Williamson, S.; Carrington, A.L.; Boulton, A.J. Multicenter Study of the Incidence of and Predictive Risk Factors for Diabetic Neuropathic Foot Ulceration. Diabetes Care 1998, 21, 1071-1075. [CrossRef]

13. Macgilchrist, C.; Paul, L.; Ellis, B.M.; Howe, T.E.; Kennon, B.; Godwin, J. Lower-limb risk factors for falls in people with diabetes mellitus. Diabetic Med. 2010, 27, 162-168. [CrossRef] [PubMed]

14. Allet, L.; Armand, S.; de Bie, R.A.; Golay, A.; Pataky, Z.; Aminian, K.; de Bruin, E.D. Clinical factors associated with gait alterations in diabetic patients. Diabetic Med. 2009, 26, 1003-1009. [CrossRef] [PubMed]

15. Ward, R.E.; Boudreau, R.M.; Caserotti, P.; Harris, T.B.; Zivkovic, S.; Goodpaster, B.H.; Satterfield, S.; Kritchevsky, S.B.; Schwartz, A.V.; Vinik, A.I.; et al. Sensory and motor peripheral nerve function and incident mobility disability. J. Am. Geriatr. Soc. 2014, 62, 2273-2279. [CrossRef] [PubMed]

16. Dixon, C.J.; Knight, T.; Binns, E.; Ihaka, B.; O’Brien, D. Clinical measures of balance in people with type two diabetes: A systematic literature review. Gait Posture 2017, 58, 325-332. [CrossRef] [PubMed]

17. Deng, H.; He, F.; Zhang, S.; Calleman, C.J.; Costa, L.G. Quantitative measurements of vibration threshold in healthy adults and acrylamide workers. Int. Arch. Occup. Environ. Health 1993, 65, 53-56. [CrossRef] [PubMed]

18. Weir, J.P. Quantifying test-retest reliability using the intraclass correlation coefficient and the SEM. J. Strength Cond. Rres. 2005, 19, 231-240. [CrossRef]

19. Shrout, P.E.; Fleiss, J.L. Intraclass correlations: Uses in assessing rater reliability. Psychol. Bull. 1979, 86, 420-428. [CrossRef]

20. Munro, B.; Visintainer, M.; Page, E. Statistical Methods for Health Care Research; Lippincott Williams \& Wilkins: Philadelphia, PA, USA, 1986.

21. Riandini, T.; Wee, H.L.; Khoo, E.Y.; Tai, B.C.; Wang, W.; Koh, G.C.; Tai, E.S.; Tavintharan, S.; Chandran, K.; Hwang, S.W. Functional status mediates the association between peripheral neuropathy and health-related quality of life in individuals with diabetes. Acta Diabetol. 2018, 55, 155-164. [CrossRef]

22. Boucher, P.; Teasdale, N.; Courtemanche, R.; Bard, C.; Fleury, M. Postural stability in diabetic polyneuropathy. Diabetes Care 1995, 18, 638-645. [CrossRef]

23. Martinelli, A.R.; Mantovani, A.M.; Nozabieli, A.J.L.; Ferreira, D.M.A.; Barela, J.A.; de Camargo, M.R.; Fregonesi, C.E.P.T. Muscle strength and ankle mobility for the gait parameters in diabetic neuropathies. Foot 2013, 23, 17-21. [CrossRef]

24. Manor, B.; Li, L. Characteristics of functional gait among people with and without peripheral neuropathy. Gait Posture 2009, 30, 253-256. [CrossRef] [PubMed]

25. Richardson, J.K.; Hurvitz, E.A. Peripheral neuropathy: A true risk factor for falls. J. Gerontol. Ser. A Biol. Sci. Med. Sci. 1995, 50, M211-M215. [CrossRef] [PubMed]

26. Wongsurawat, N.; Armbrecht, H.J. Insulin modulates the stimulation of renal 1, 25-dihydroxyvitamin D3 production by parathyroid hormone. Acta Endocrinol. 1985, 109, 243-248. [CrossRef] [PubMed]

27. Pietschmann, P.; Schernthaner, G.; Woloszczuk, W. Serum osteocalcin levels in diabetes mellitus: Analysis of the type of diabetes and microvascular complications. Diabetologia 1988, 31, 892-895. [CrossRef] [PubMed] 
28. Schwartz, A.V.; Sellmeyer, D.E.; Ensrud, K.E.; Cauley, J.A.; Tabor, H.K.; Schreiner, P.J.; Jamal, S.A.; Black, D.M.; Cummings, S.R.; Study of Osteoporotic Fractures Research Group. Older women with diabetes have an increased risk of fracture: A prospective study. J. Clin. Endocrinol. Metab. 2001, 86, 32-38. [CrossRef] [PubMed]

29. Alfonso-Rosa, R.M.; Del Pozo-Cruz, B.; Del Pozo-Cruz, J.; Sanudo, B.; Rogers, M.E. Test-retest reliability and minimal detectable change scores for fitness assessment in older adults with type 2 diabetes. Rehabil. Nurs. 2014, 39, 260-268. [CrossRef]

30. Beckerman, H.; Roebroeck, M.E.; Lankhorst, G.J.; Becher, J.G.; Bezemer, P.D.; Verbeek, A.L. Smallest real difference, a link between reproducibility and responsiveness. Qual. Life Res. 2001, 10, 571-578. [CrossRef]

31. Brown, S.J.; Handsaker, J.C.; Bowling, F.L.; Boulton, A.J.; Reeves, N.D. Diabetic peripheral neuropathy compromises balance during daily activities. Diabetes Care 2015, 38, 1116-1122. [CrossRef]

32. Lafond, D.; Corriveau, H.; Prince, F. Postural control mechanisms during quiet standing in patients with diabetic sensory neuropathy. Diabetes Care 2004, 27, 173-178. [CrossRef]

(C) 2019 by the authors. Licensee MDPI, Basel, Switzerland. This article is an open access article distributed under the terms and conditions of the Creative Commons Attribution (CC BY) license (http://creativecommons.org/licenses/by/4.0/). 